\author{
Military Technical College \\ Kobry El-Kobbah, \\ Cairo, Egypt.
}

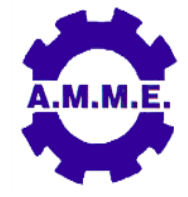

\title{
EXPERIMENTAL INVESTIGATION OF THE EFFECT OF NUMBER OF LAYERS AND FLOW ARRANGEMENT ON THE PERFORMANCE OF A MICROCHANNEL HEAT SINK SYSTEM
}

\author{
H. Abdel Aty ${ }^{1, \star}$, O. Hassan ${ }^{1}$, M. Abdelgawad ${ }^{1}$ and N. Y. Abdel-Shafi ${ }^{1}$
}

\begin{abstract}
This paper presents experimental investigation of the effect of number of layers as well as the flow arrangement on the performance of a microchannel heat sink system (MCHS). The effect of flow rate on pressure drop, temperature uniformity, and outlet temperature in single and double layers MCHS under the effect of uniform heat flux condition was investigated. The MCHS used had micro channels with rectangular cross section. The heat flux applied during the experiments was varied from 5.0 to $13.68 \mathrm{~W} / \mathrm{cm}^{2}$. The results of single layer $\mathrm{MCHS}$ were compared with theoretical predictions in order to validate the results of the present test rig. From the obtained results it was observable that the outlet temperature was highly dependent on the mass flow rate until a certain value after which change in the outlet temperature was minor. On the other hand, the pressure drop increased almost linearly with the increase in mass flow rate due to laminar nature of the flow. When multilayer systems were tested, the main observation was a significant reduction in the pressure drop compared to the single layer case for the same mass flow rate. Moreover, flow arrangement was found to have an impact on pressure drop which was smaller in the case of counter flow arrangement compared to parallel flow arrangement case. Flow configuration (parallel, counter, or cross-flow) had a significant effect on temperature uniformity over the heat sink area with counter-flow arrangement giving best temperature uniformity followed by the cross-flow arrangement. Change in the outlet temperature in the case of multilayer and single layer systems was not significate which may be due to the fact that the same mass flow rate was applied to all tested cases.
\end{abstract}

\section{KEYWORDS}

Micro channel heat sink, multi-layer, flow arrangement, experimental investigation.

Mechanical Engineering Department, Assiut University, Assiut 71516, Egypt Corresponding Author, E-mail eng_hassan_mech@yahoo.com. 


\section{NOMENCLATURE}

C

$\mathrm{h}$

$\mathrm{H}$

k

L

$\dot{\mathrm{m}}$

P

$\Delta \mathrm{P}$

q"

$\dot{Q}$

$\mathrm{T}$

$\Delta \mathrm{T}$

W
Specific heat

Heat transfer coefficient

Height

Thermal conductivity

Length

Mass flow rate

Pressure

Pressure drop

Heat flux

Heat transfer rate

Temperature

Temperature difference

Width

\section{Greek Letters}

$\rho$

Density

\section{Subscripts}

C

copper

w

water

\section{Abbreviations}

MCHS

Micro Channel Heat Sink

\section{INTRODUCTION}

Microchannel heat sinks (MCHS) emerged in the last few decades as a strong candidate for cooling of computer microprocessors with its ever-increasing power. MCHS were reported to be capable of removing heat fluxes up to hundreds of Watts per square centimeter which attracted many researchers to study its performance in details. However, the majority of previous studies conducted in this area were numerical. This is attributed to the difficulties in the fabrication of such micro-scaled systems and the need for a high-pressure pumping source to force the flow inside the tinny sized channels. MCHS can be classified according to number of layers (single, double, and multilayer), channel cross section (e.g. rectangular, triangular, circular), and flow configuration (parallel, counter, and cross-flow). 
Previous studies in the area of Micro Channel Heat Sink systems can be divided into many research directions. The first research direction is concerned with numerical simulations of the effect of geometrical parameters on the performance of single layer MCHS systems. Sui et al. [1] Investigated the effect of variable wave length of wavy walled micro channel on the fluid flow and heat transfer. Kim et al. [2] investigated the effect of changing the channel cross section (e.g. rectangular, inverse trapezoidal, triangular, trapezoidal and diamond-shaped) on the MCHS performance. Kumaran et al. [3] investigated the effect of changing the header shape on the MCHS performance. They considered rectangular, triangular and trapezoidal configurations. Also, location of the inlet and outlet ports (e.g. I, C, V, Z and U-type arrangements) on flow mal-distribution in parallel micro-channels was investigated. Tan et al. [4] investigated the effect of making hollows with different cross section shapes (circular, rectangular and trapezoidal) in a rectangular fin on its performance. Zhao et al. [5] investigated the effect of geometry features, porosity and rotated angle for pin fin MCHS on its performance. Rostami et al. [6] investigated the effect of wavy wall MCHS on pressure drop, heat transfer and temperature uniformity along single MCHS surface. Also, Singh et al. [7] studied the effect of cross section design as in the previously mentioned studies, however; they considered other configurations such hexagonal and circular cross sections. Based on the findings of the previously mentioned studies it was clear that the heat transfer coefficient is maximum with the circular cross section MCHS followed by the hexagonal, then the rectangular, then the triangular ones. Also, wavy walled $\mathrm{MCHS}$ are accompanied with higher heat transfer coefficient than that of flat walled ones.

The second research direction is concerned with the effect of the cooling fluid type on heat transfer enhancement from the MCHS system. Ebrahimi et al. [8] investigated the Heat transfer and entropy generation in a MCHS with longitudinal vortex generators using nanofluids. Water- $\mathrm{Al}_{2} \mathrm{O}_{3}$ and water-CuO nanofluids with different nanoparticle volume-fractions and sizes were compared to pure-water as working fluids. It was clear from this study and other similar studies that using nanofluid enhances the thermal conductivity of the fluid, decreases the thermal resistance and improves the uniformity of temperature distribution on the base surface of MCHS compared with the pure fluid case. Meanwhile using nanofluids leads to higher pressure drop when compared with pure fluid case.

The third research direction is concerned with the effect of number of MCHS system layers on the performance. Vafai et al [9] investigated the thermal performance, the temperature distribution and presented a procedure for optimizing the geometrical design parameters of double layered MCHS systems. Xie et al. [10] also presented a similar study to that of Vafai et al. however; they considered wavy and straight walled MCHS systems. They also considered the effect of the flow configuration, parallel and counter, and the effect of wave amplitude and volumetric flow ratio on the temperature distributions and thermal resistance. Adewumi et al. [11] investigated the effect of flow arrangement, parallel and counter, on the peak temperature of the substrate. They tried to optimize the dimensions of the multi-layered microchannel in terms of the channel hydraulic diameter, channel aspect ratio, solid volume fraction, for the fixed solid volume that minimized the peak temperature and maximized the thermal conductance. Effat et al. [12] in a similar study to that of Adewumi et al. investigated the effect of flow arrangement and number of layers on the thermal performance of a multi-layer MCHS. They considered a number of layers of up to three and parallel and counter flow arrangements were considered. Based on these 
studies it was clear that increasing number of MCHS layers lead to a decrease pressure drop and a more uniform surface temperature. Moreover the counter flow arrangement gives better uniform temperature than other flow arrangement cases.

In terms of experimental research efforts in the area of MCHS, Wu et al. [13] investigated the convective heat transfer in silicon trapezoidal MCHS with different surface conditions. Steinke et al. [14] investigated the thermal performance of straight rectangular micro channel. Ho [15] studied the pressure drop and heat transfer in single phase staggered square finned MCHS. Zhang et al. [16] conducted a comparative study between straight, $U$ shape and serpentine MCHS. Gawali et al. [17] investigated the heat transfer characteristic, through a rectangular MCHS. Manay et al. [18] invetigated the effects of microchannel height and particle volume fraction of nanofluids on heat transfer and pressure drop characteristics. Deng et al. [19] conducted a comparative study between rectangular and reentrant rectangular micro channel (the upper part of channel is rectangular and the lower part is circular). From the previously mentioned literature the following points can be summarized;

1. Majority of research studies conducted in the area of MCHS systems is numerical and as a result more experimental effort are essential in this area.

2. Multi-layered MCHS systems showed promising performance when numerically studied, and as a result more investigations are still essential to maximize the heat flux that can be extracted from such systems.

Consequently, the aim of this present study is to experimentally investigate the effect of number of layers and flow arrangement on the performance of a rectangular cross section multi-layered MCHS system.

\section{EXPERIMENTAL SETUP}

The schematic of the MCHS system test rig installed in Assiut University is shown in Fig. 1a the facility is composed mainly of a micro gear pump, a power supply, heaters, pressure sensors, temperature sensors, MCHS Unit, supply and disposed water tanks, temperature and pressure display units and piping and wiring network. An Image of the installed components is shown in Fig. 1b ,1c and the detailed specifications of different items are as follows:

1. Micro gear pump; Cole-Parmer Gear Pump System, Analog Drive, 0.092 $\mathrm{mL} / \mathrm{rev}$. Maximum Differential pressure $75 \mathrm{psi}$. Flow rate $(\mathrm{min}) 4.60 \mathrm{~mL}$ at 50 $\mathrm{rpm}$ and $331.2 \mathrm{~mL}$ at $3600 \mathrm{rpm}$.

2. Power supply; a variable power supply, Vin $220 \mathrm{~V} \mathrm{AC}$ and $50 \mathrm{~Hz}$, is employed as the main power source of the heaters with a variable output voltage and current, Vout: 0 - 30V, lout: 0 - 10A. This helps supply variable heat fluxes.

3. Pressure sensor: pressure rang $\pm 100 \mathrm{PSI}( \pm 689.48 \mathrm{kPa})$ Port Size (Male - 0.14" $(3.56 \mathrm{~mm})$ Tube, Barbed. Output $(0 \mathrm{mV} \sim 100 \mathrm{mV})$. Voltage - Supply (2.5 V 16 V).

4. Temperature display; Six Channel Handheld Temperature Data Logger for thermocouples Type J, K, T, E, R, S.

5. Temperature sensors; Thermocouples of types $\mathrm{K}$ and $\mathrm{T}$ with different junction diameter.

6. Water tanks; a $500 \mathrm{ml}$ water tank is used in order to ensure continuous water flow during the experiment period. Meanwhile, two small jars are used to collect disposed water coming out of the MCHS unit. 
7. Heaters; a number of 4 pin heaters, 40 Watts each, are plugged into an aluminum block, $30 \times 30 \times 30 \mathrm{~mm}^{3}$, with a carefully chosen height to ensure uniform heat flux condition beneath the MCHS unit.

8. MCHS unit; with rectangular micro channels $305 \mu \mathrm{m}$ wide and $90 \mu \mathrm{m}$ apart fabricated in $110\left(99 \%\right.$ pure) copper plate $\left(\mathrm{k}_{\mathrm{c}}=390.88 \mathrm{~W} / \mathrm{m} . \mathrm{K}, \mathrm{C}_{\mathrm{c}}=385 \mathrm{~J} / \mathrm{kg} . \mathrm{K}\right.$, $\left.\rho_{\mathrm{c}}=8912.92 \mathrm{~kg} / \mathrm{m} 3\right)$ and the coolant used is water $\left(\mathrm{k}_{w}=0.6 \mathrm{~W} / \mathrm{m} . \mathrm{K}, \mathrm{C}_{w}=4180\right.$ $\mathrm{J} / \mathrm{kg} \cdot \mathrm{K}, \rho_{\mathrm{w}}=1000 \mathrm{~kg} / \mathrm{cm}^{3}$ ). The overall dimensions of the MCHS unit are $30^{*} 30$ $\mathrm{mm}$ (without external wall width $28^{\star} 26 \mathrm{~mm}$ ).

9. Insulation; Spray polyurethane foam $(k=0.022-0.024 \mathrm{~W} / \mathrm{m} . \mathrm{K})$ was used to minimize the heat loss from the MCHS unit to the surrounding ambient. The MCHS is covered with an acrylic cover of $10 \mathrm{~mm}$ thickness, as shown in Fig.2.

10. Thermal grace; $(k>0.925 \mathrm{~W} / \mathrm{m} . \mathrm{k})$ was employed to fill the air gaps between the aluminum block and the pin heaters and between the aluminum block and the MCHS. ,

11. Tubing; $3 \mathrm{~mm}$ inner diameter plastic tubing is used to connect the supply tank, the gear pump, the MCHS unit and the disposed water tanks.

12. Flow rate was measured by a stop watch and a calibrated beaker.

\section{MCHS FABRICATION METHOD}

The MCHS units used in in the present study were fabricated by photolithography technique. The details of the procedure followed are;

1- Positive photoresist, AZ ECI 3027, was spin coated on pure copper sample (10 seconds at 500 r.p.m with an acceleration of $50 \mathrm{rad} / \mathrm{s}^{2}$ and 50 second at 3000 r.p.m with an acceleration of $300 \mathrm{rad} / \mathrm{s}^{2}$ ) and baked on a hotplate ( softback at $85^{\circ} \mathrm{C}$ and $120 \mathrm{sec}$ ).

2- The photoresist was exposed to UV light on a pattern generator (Heidelberg $\mu$ PG101, Heidelberg, Germany) and slides were baked on a hot plate (postbake at $110^{\circ} \mathrm{C}, 120 \mathrm{sec}$ ).

3- Sample were then developed in AZ MIF 326 developer for 2 minutes and etched in Ferric chloride for 2 Minutes (concentration: $1 \mathrm{gram}$ FCl $/ 250 \mathrm{ml}$ Water).

4- Remaining photo resist was stripped in AZ100 remover.

Figure $2 \mathrm{a}$ is an image of a finished MCHS unit fabricated according to the previously mentioned procedure and Fig. $2 \mathrm{~b}$ a scanning electron microscope (SEM) photograph showing the accuracy of the Unit.

\section{VAIDATION OF THE TEST FACILITY}

In order to vaidate the output of the present facility, a single layer MCHS unit was considered. The flow rate range was from $\dot{m}=0.18248 \mathrm{~g} / \mathrm{s}$ to $4 \mathrm{~g} / \mathrm{s}$. This range was selected to ensure single phase flow along the entire length of the MCHS without boiling. Fig 3 is a comparison between experimental measurements and analytical predications, Eqs.1and 2, of the temperature difference across the MCHS unit at different mass flow rates. From the figure it is clear that there is a good agreement between the two cases. The minor differences in the temperature difference are attributed to the heat loss to the surrounding atmosphere through the insulation that shrouds the unit. 
$\dot{Q}=\dot{m} C_{p} \Delta T$, where $\Delta T=T_{o}-T_{I}$

So $\Delta T=\frac{\dot{Q}}{\dot{m} C p}$

As shown in Fig. 3b it is observable that the MCHS efficiency, Eq. 3. is higher than $90 \%$ all over the tested range of mass flow rates and heat fluxes. Based on the information presented in Figs. $3 a$ and $3 b$, it is clear that the results obtained from the facility are accurate and the error is within the range of uncertainty.

MCHS efficiency $\eta=\frac{\text { heat } \text { transf er rate to cooling water }}{\text { power consumed by four heaters }}=\frac{\dot{m} C_{p} \Delta T}{V * I}$

\section{RESULTS AND DISCUSSIONS}

\section{Single Layer MCHS}

The single layer MCHS unit is presented here as a base line case for performance comparison purposes. A side from comparison purposes, performance of the single layer MCHS was as expected. Temperature difference between outlet and inlet flow was inversely proportional to the mass flow rate, Fig. 4-a. At small mass flow rates, $\dot{m}<0.75 \mathrm{~g} / \mathrm{s}$, any change in the coolant flow rate results in significant change in the temperature difference. However; for larger mass flow rates, $\dot{m}>0.75 \mathrm{~g} / \mathrm{s}$, the change in the temperature difference as a result of mass flowrate change is very small. The change in the pressure drop across the MCHS as a result of mass flow rate change has an opposite trend to that of the temperature difference, Fig. 4-b. For $\dot{m}<0.75 \mathrm{~g} / \mathrm{s}$, the change in pressure drop due to mass flowrate changes is negligible. This indicates the existence of a trade-off between cooling performance and pressure drop when it comes to choosing the optimum flow rate.

We noticed that increasing mass flow rate results in an almost linear increase of the pressure drop due to the increased shear stress on microchannel walls. This linear increase is expected since flow in the microchannels forming the MCHS is laminar $(R e \leq 1000)$. This effect is further magnified due to the decrease in coolant temperature, and subsequent increase in viscosity at high mass flow rates, which leads to high viscosity, high surface shear force, and even higher pressure drop. On the other hand, increasing the heat flux resulted in a slight decrease in pressure drop due to reduction in liquid viscosity at the higher generated temperatures.

\section{Double Layer MCHS}

Adding a second layer of microchannels to the MCHS produces new possibilities for configuring flow of the liquid inside the MCHS. In addition to parallel flow arrangement which is the most intuitive with the flow in the bottom and top microchannel layers moving in the same direction, counter flow and cross flow arrangements are also possible. In Counter flow arrangement, liquid in the top microchannel layer flows in an opposite direction to liquid in the bottom layer, whereas in cross flow arrangement, flow in the top layer is perpendicular to flow in the bottom layer. In the next few sections we will study the effect of these three flow 
arrangements on performance of the MCHS using single-layer MCHS as the base of comparison.

\section{Effect of number of layers and flow arrangement on pressure drop}

The most significant effect on adding a second microchannel layer to the MCHS is the huge reduction (about three folds) in pressure drop at the same mass flow rate, Fig 5.This is caused by cutting down the flow in each layer to half its value in the single MCHS. The flow arrangement itself did not have a significant effect on the pressure drop with pressure variations expected to be because of changes in liquid viscosity in each case due to changes in temperature distribution. For example, counter-flow arrangement gave the lowest pressure drop because it exhibits high temperature, and thus lower viscosity, for longest length of the microchannel compared to parallel- and cross-flow cases as discussed in the next section. The numerical findings of Effat et al [12], supports the present ones as they stated that the pressure drop associated with counter flow arrangement is lower than that of parallel flow as well.

\section{Effect of number of layers and flow arrangement on temperature uniformity and outlet temperature}

Adding the second microchannel layer did not reduce the outlet temperature of the coolant since flow rate and heat flux was fixed when comparing single-layer and double-layer MCHS which should result in the same temperature difference between the outlet and inlet streams according to equation (1), Fig 6-a. A better criterion for assessing benefit of adding the second layer is measuring the temperature on the heated surface itself not the outlet flow. However this was not possible with the current available measurement tools.

On the other hand, flow configuration significantly affected the temperature distribution on the MCHS, Fig. 6-b. At low flow rates, counter-flow arrangement showed better uniformity in temperature distribution along the top microchannel layer because, unlike parallel flow arrangement, cold liquid is introduced to the MCHS from both sides. Such experimental results agree well with the numerical results mentioned by Effat et al. [12]. As expected, cross-flow arrangement showed intermediate temperature uniformity between counter- and parallel-flow arrangements.

\section{CONCLUSION}

In this paper, experimental investigation of the effect of number of layers single and double, as well as the flow arrangement on the performance of a microchannel heat sink system (MCHS) was presented. The effect of flow rate on pressure drop, outlet temperature of the coolant, and temperature uniformity on single and double layers under the effect of uniform heat flux condition was considered. The MCHS used had micro channels with rectangular cross section ( $\mathrm{W} \times \mathrm{H} \approx 300 \times 100 \mu \mathrm{m})$. The heat flux applied during the experiments was varied from 5.0 to $13.68 \mathrm{~W} / \mathrm{cm}^{2}$. The results obtained can be summarized in the following points;

1 - The outlet temperature is highly dependent on the mass flow rate until a certain value, after which change in the outlet temperature was minor, for both single and double layer cases. 
2- The pressure drop accompanying the application of multilayer concept is significantly small when compared to the single layer case for the same mass flow rate.

3- The flow arrangement has a slight impact on the pressure drop whereas it has a clear impact on the temperature uniformity over the heat sink area.

\section{REFERENCES}

1. Sui, Y., et al., "Fluid Flow and Heat transfer in Wavy Microchannels", International Journal of Heat and Mass Transfer, 2010, pp. 2760-2772.

2. Kim, S.-M. and I. Mudawar, "Analytical Heat Diffusion Models for Different Micro-channel Heat Sink Cross-sectional Geometries", International Journal of Heat and Mass Transfer, 2010, pp. 4002-4016.

3. Manikanda Kumaran, R.et al., "Experimental and Numerical Studies of Header Design and Inlet/Outlet Configurations on Flow Mal-distribution in Parallel Micro-channels", Applied Thermal Engineering, 2013,pp. 205-216.

4. H. J. Tony Tan et al., "Effect Of Geometry And Number Of Hollow On The Performance of Rectangular Fins in Micro Channel Heat Sink", J. of Thermal Science and Technology, 2013.

5. Jin Zhao, et al.," Numerical Studies on Geometric Features of Microchannel Heat Sink with Pin Fin Structure", 4th Micro and Nano Flows Conference,2014.

6. Rostami, J., et al., "Optimization of Conjugate Heat Transfer in Wavy Walls Microchannels"., Applied Thermal Engineering, 2015,pp. 318-328.

7. Harpreet Singh and Harpreet Singh Randhawa, "Numerically Study on Heat Transfer Performance of Micro Channels Heat Sink with Different Shape by using N-Octane", International Journal for Innovative Research in Science \& Technology, Volume 1,No 10,2015.

8. Ebrahimi, A.,et al.,"Heat Transfer and Entropy Generation in a Microchannel with Longitudinal Vortex Generators using Nanofluids"., Energy, 2016, pp. 190201.

9. Kambiz Vafai and Lu Zhu," Analysis of Two-layered Micro-channel Heat Sink Concept in Electronic Cooling", International Journal of Heat and Mass Transfer ,1999.

10. Xie, G., et al., "Comparative Study of the Flow and Thermal Performance of Liquid-Cooling Parallel-Flow and Counter-Flow Double-Layer Wavy Microchannel Heat Sinks"., Numerical Heat Transfer, Part A, 2013, pp. 30-55.

11. OlayinkaO.Adewumi,T.B.-O.a.J.P.M.,"Geometric Optimization Of Multil-Layered Microchannel Heat Sink With Different Flow Arrangement"., Proceedings of the 15th Heat Transfer Conference, IHTC-15, 2014.

12 M. B. Effat, et al., "Numerical Invistigation Of The Effect of Flow Arrangment and Number of Layers on The Performance of Multi-Layer Microchannel Heat Sink"., Proceedings of the ASME 2015 International Mechanical Engineering Congress \& Exposition, IMECE2015, 2015.

13. Wu, H.Y. and P. Cheng, "An Experimental Study of Convective Heat Transfer in Silicon Microchannels with Different Surface Conditions"., International Journal of Heat and Mass Transfer, 2003, pp. 2547-2556.

14. Steinke, M.E. and S.G. Kandlikar, "Single-phase Liquid Friction Factors in Microchannels. International Journal of Thermal Sciences", 2006,pp. 10731083. 
15. Ho, A.M.S., et al., "Pressure Drop and Heat Transfer in a Single-Phase MicroPin-Fin Heat Sink",in2006 ASME International Mechanical Engineering Congress and Exposition,IMECE2006-14777. 2006. pp. 213-220.

16. Zhang, T.T., et al., "Numerical Simulation of Fluid Flow and Heat Transfer in UShaped Microchannels. Numerical Heat Transfer", Part A: Applications, 2014,pp. 217-228.

17. B. S. Gawali et al.," Theoretical and Experimental Investigation of Heat Transfer Characteristics through a Rectangular Microchannel Heat Sink", International Journal of Innovative Research in Science, Engineering and Technology, Vol. 3, No 8, 2014.

18. Manay, E. and B. Sahin, "The Effect of Microchannel Height on Performance of Nanofluids". International Journal of Heat and Mass Transfer, 2015, pp. 307320.

19. Deng, D., "Experimental and Numerical Study of Thermal Enhancement in Reentrant Copper Microchannels". International Journal of Heat and Mass Transfer, 2015. 

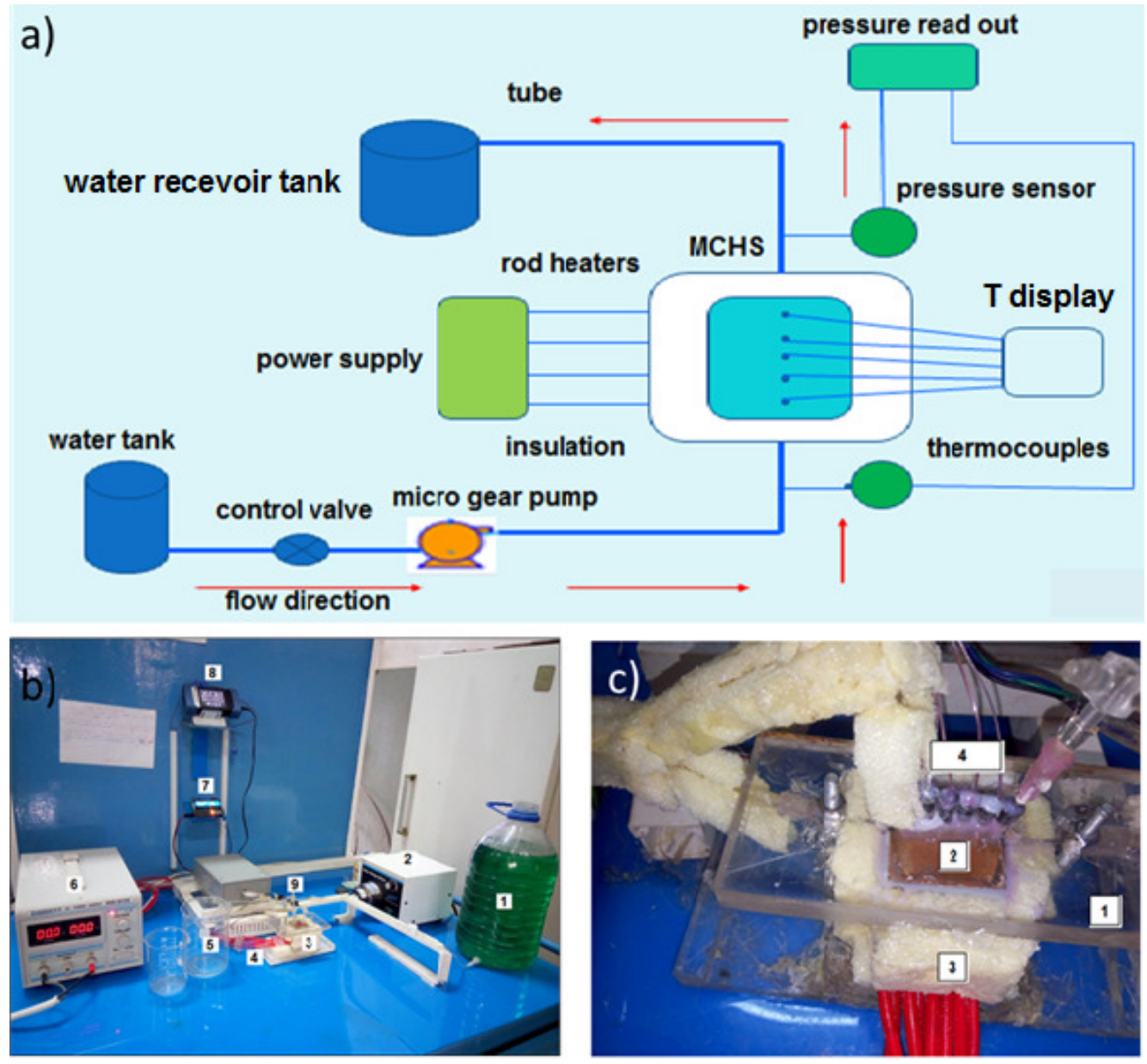

Fig. 1. Details of the test rig used to characterize the performance of MCHS. a) Schematic of the Test rig showing direction of the flow and the different components of the setup. b) Picture of the test rig showing its different components: 1) Water supply tank, 2) Gear pump, 3) MCHS, 4) heaters, 5) calibrated beaker to measure flow rate, 6) power supply, 7) Pressure readout, 8) Temperature data logger, 9) pressure sensor. C) close up on the MCHS: 1) Acrylic cover, 2) MCHS, 3) Insulation, 4) Thermocouples.
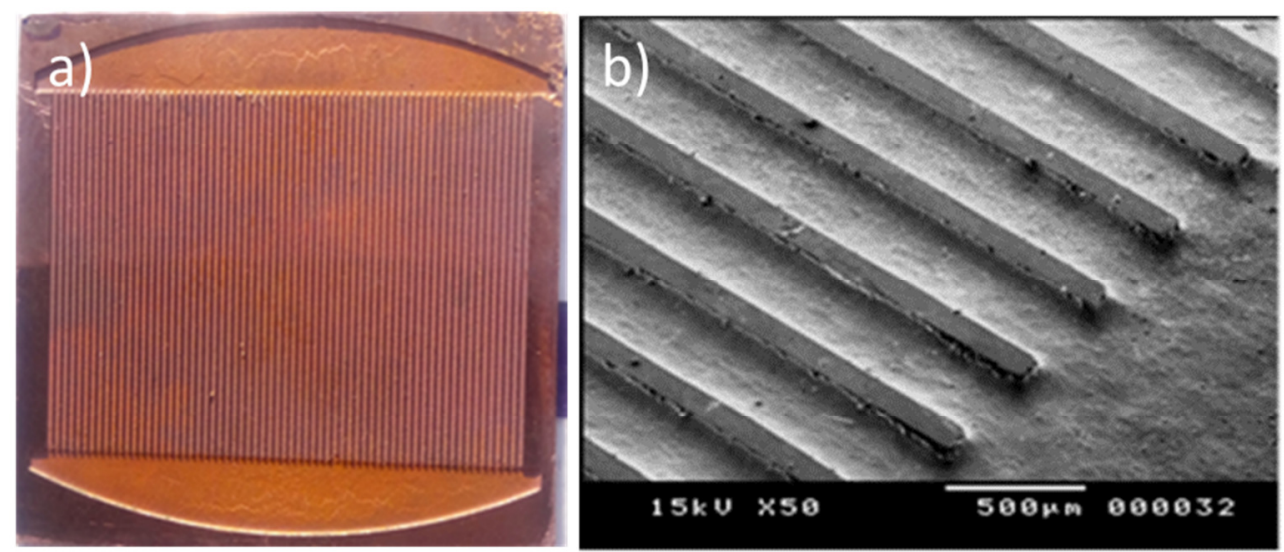

Fig. 2. a) MCHS unit after fabrication. b) Scanning electron microscope photo of the fabricted copper microchannels. 
a)

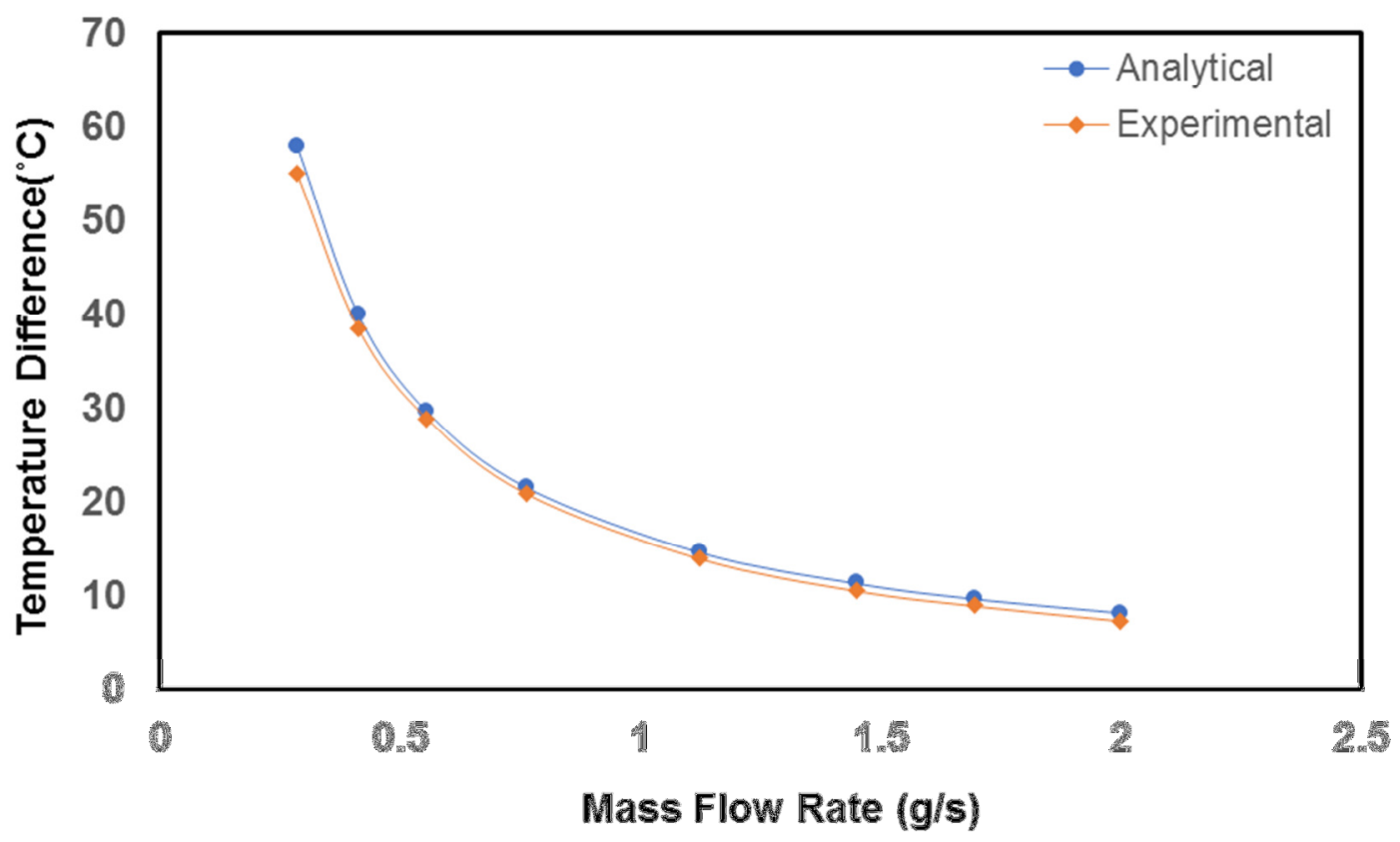

b)

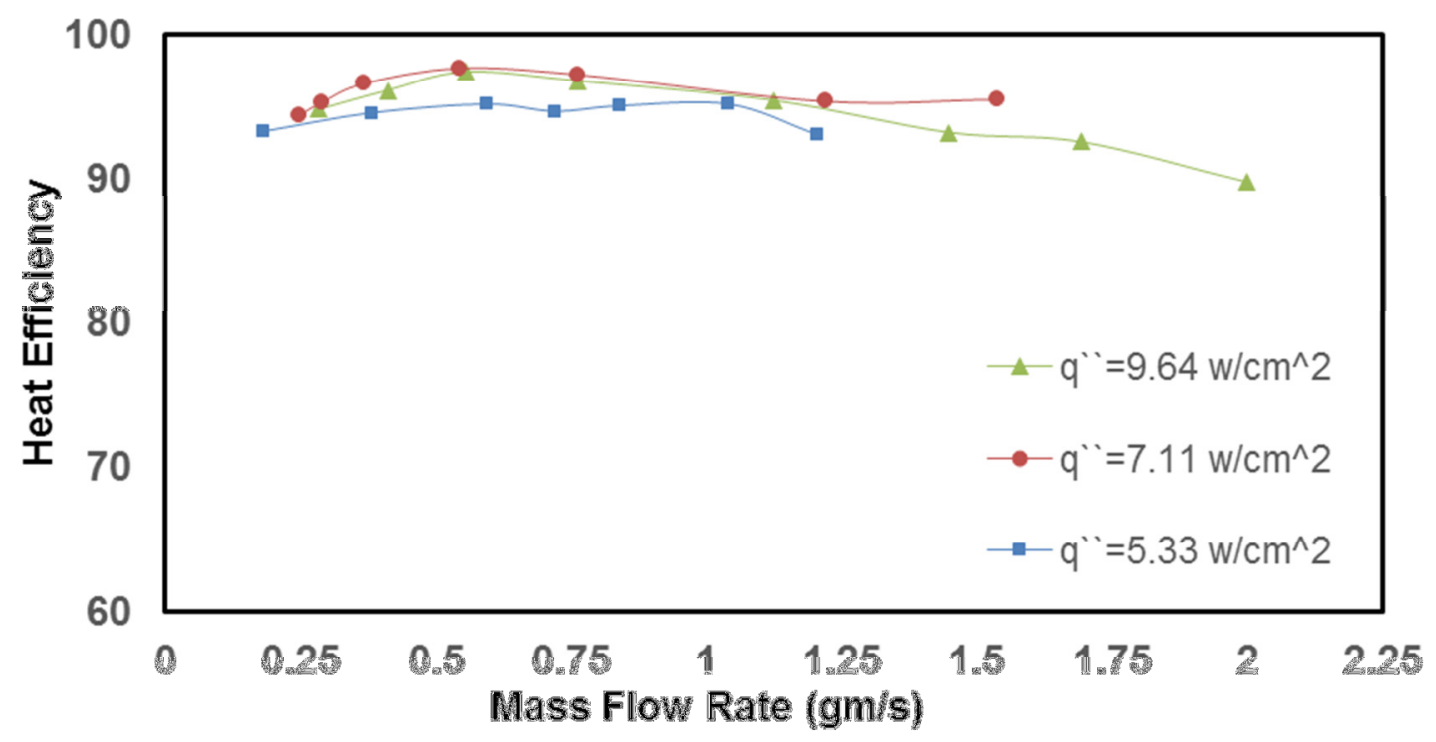

Fig. 3. Validation of the accuracy of the developed test rig. a) Comparison between measured and calculated temperature difference between water outlet and inlet as a function of the mass flow rate passing through the MCHS at a uniform constant heat flux, $q^{\prime \prime}=9.46 \mathrm{w} / \mathrm{cm}^{2}$. b) Efficiency of heat removal by the MCHS at different mass flow rates and heat fluxes 
a)

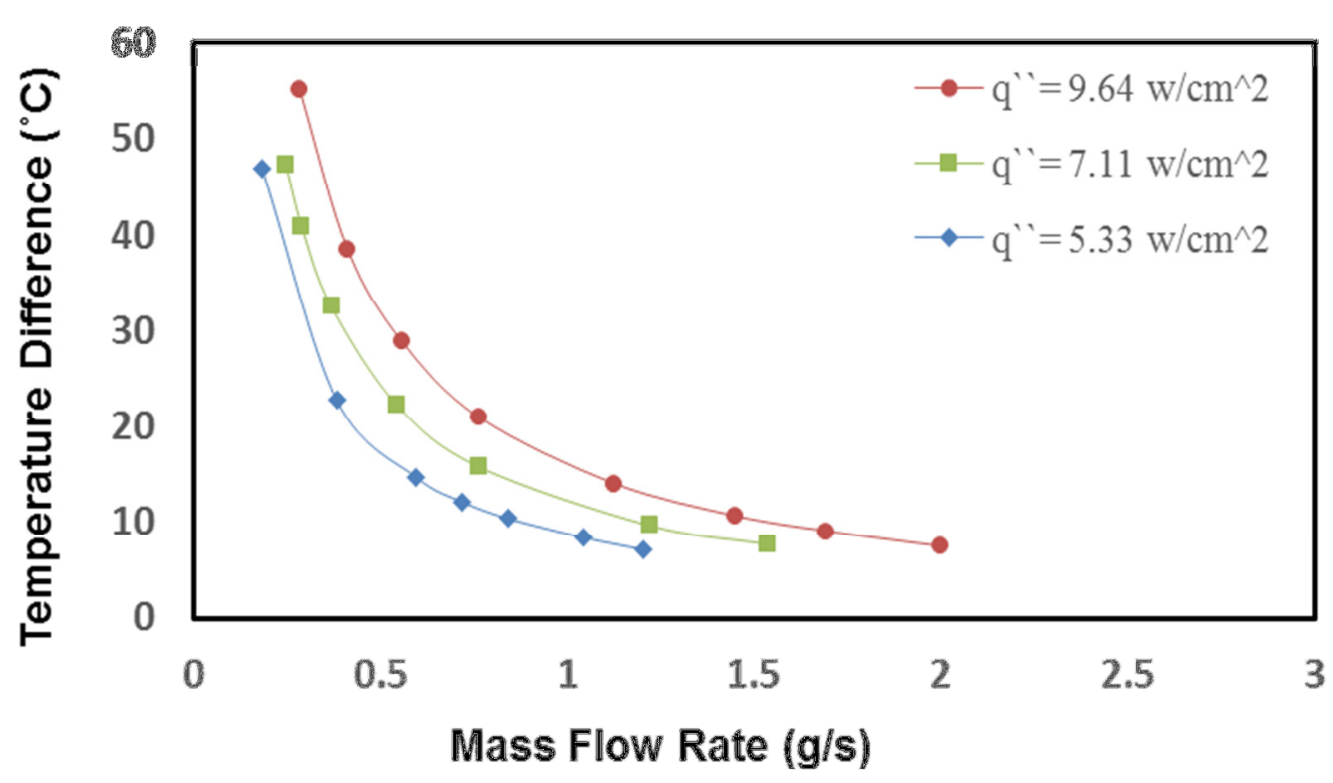

b)

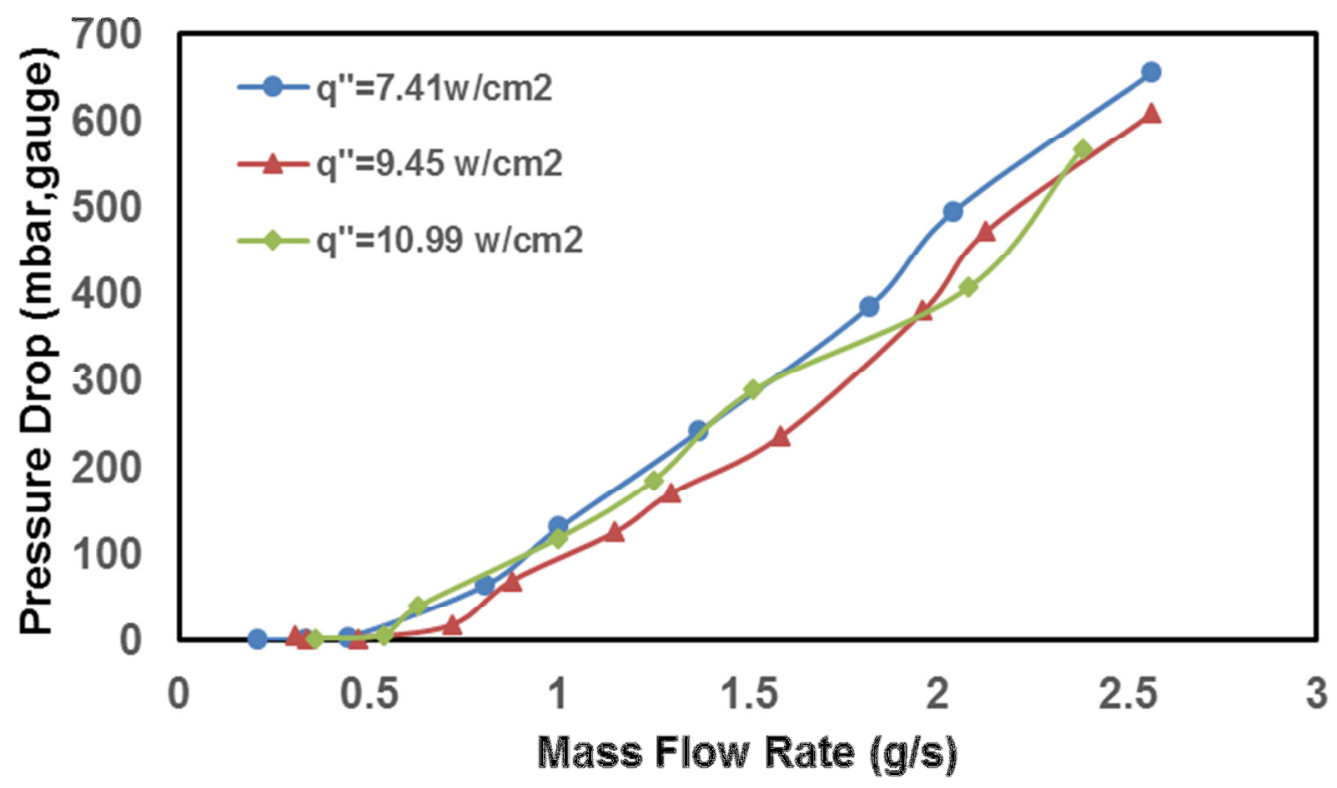

Fig. 4. a) Effect of coolant mass flow rate on the outlet-inlet temperature difference across the single layer MCHS unit at three different uniform heat fluxes. b) Effect of coolant mass flow rate on pressure drop across the single layer MCHS. 


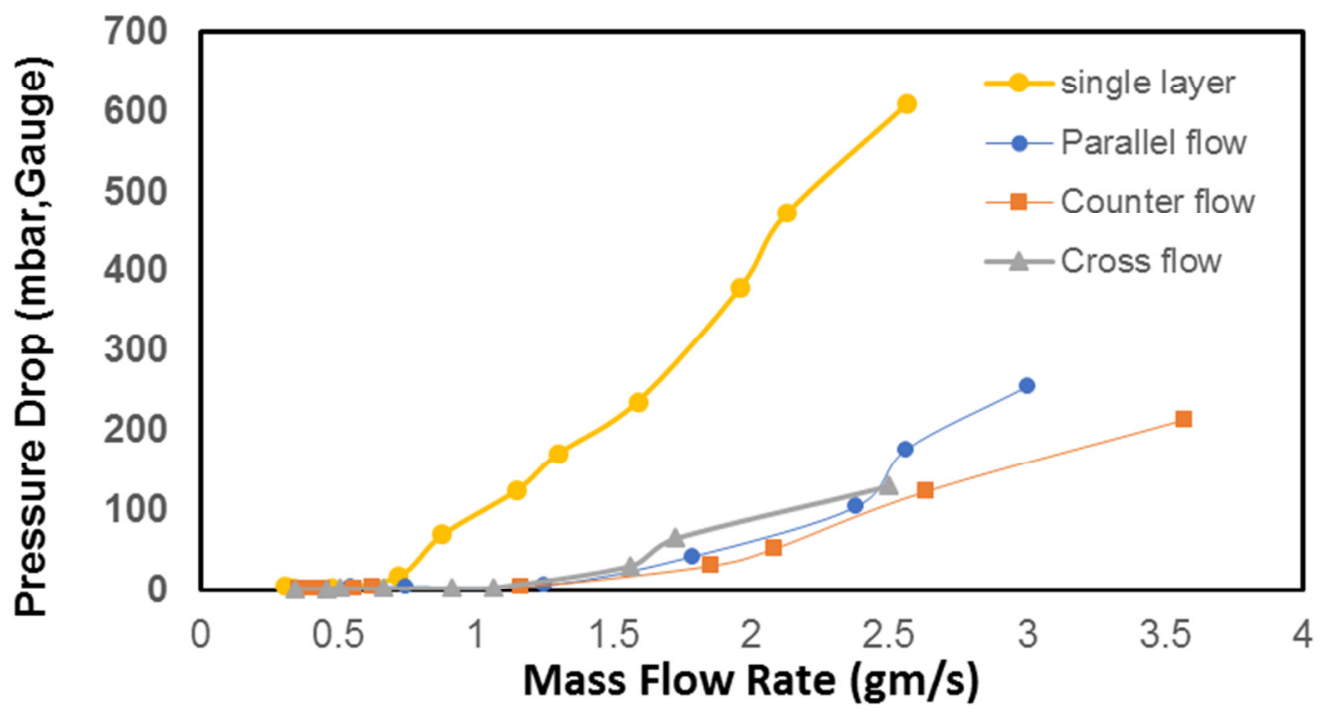

Fig. 5. Effect of coolant mass flow rate on pressure drop in case of single and double layer MCHS at three different flow arrangement parallel, cross and counter flow. The heat flux employed to capture the data in the figure is $q^{\prime \prime}=$ $13.5 \mathrm{w} / \mathrm{cm}^{2}$.

a)
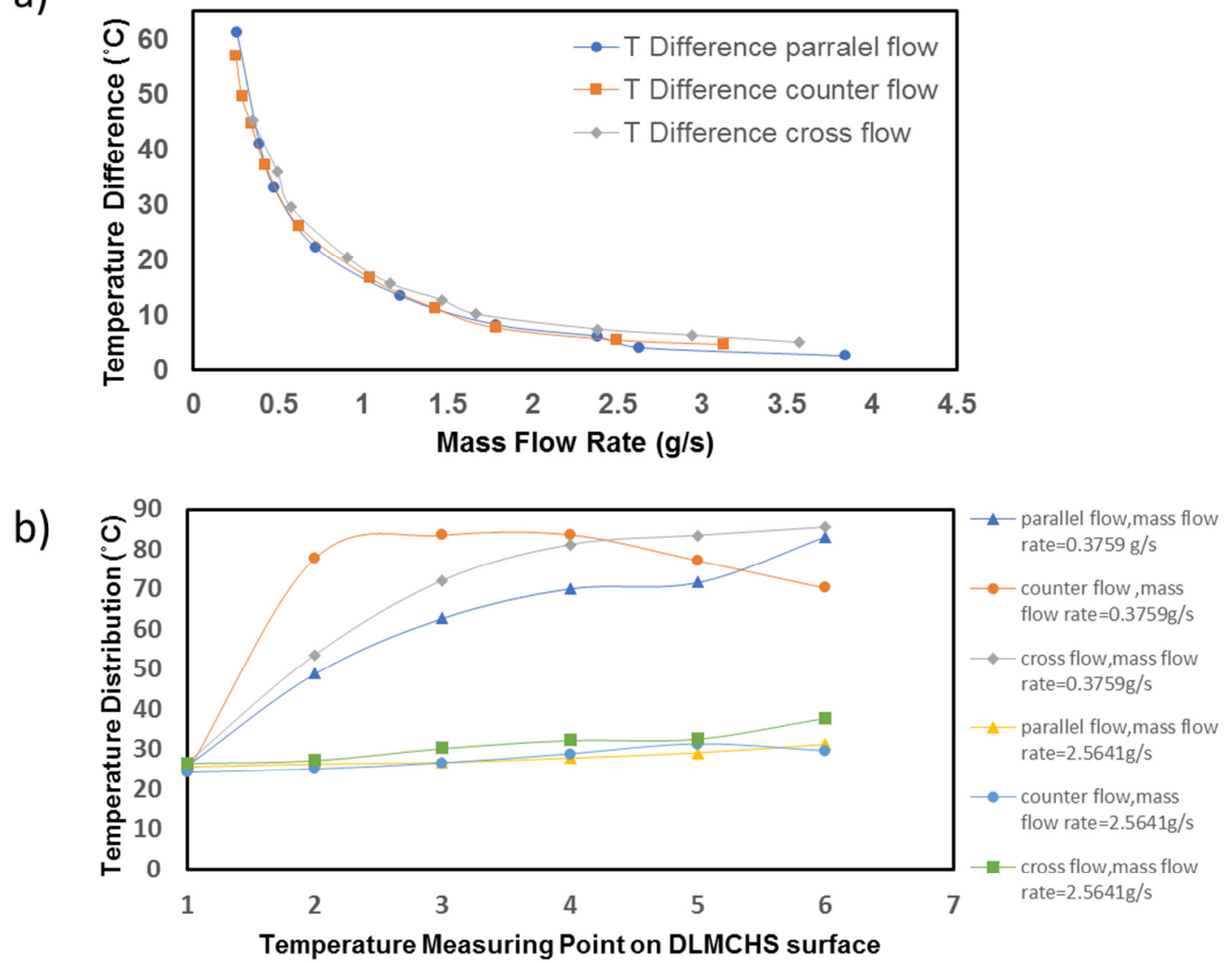

Fig. 6. a) Effect of coolant mass flow rate on outlet-inlet temperature difference at three different flow arrangements at a uniform constant heat flux $q^{\prime \prime}=13.68$ $w / \mathrm{cm}^{2}$, b) Temperature distribution along stream wise at three different flow arrangements and two different mass flow rates. 